\title{
Hydrocracking in a Gold Lined Reactor
}

\section{CATALYTIC EFFECTS OF THE REACTOR WALL}

\author{
J. M. L. Penninger \\ Eindhoven University of Technology, The Netherlands
}

The thermal cracking of hydrocarbons in the gas phase is a homogeneous reaction in the sense that the major portion of the conversion takes place in the bulk of the fluid phase. However, it has been found that the character of the reactor wall material, any pretreatment of the wall, and the age of the reactor have a profound effect on the conversion and yield of the hydrocarbon transformation. Apparently certain catalytic effects of the reactor wall are involved, so that the hydrocarbon cracking is better described as a combined homogeneous-heterogeneous reaction system.

During the last decade investigations have been carried out specifically to elucidate or to eliminate the specific catalytic effects of different reactor wall materials in hydrocarbon cracking. The usual techniques applied are the variation of the surface-tovolume ratio of the reactor, pretreatment of the reactor wall with sulphur compounds and oxygen under carefully controlled conditions, and changes in the reactor wall material (1), while even a completely wall-less reactor has been reported (2). The observations made have mainly stressed the complexity of the reactions involved in wall participation, and no conclusive picture has as yet been obtained.

Another technique applied in this field is the use of gold reactors. Gold was chosen because it has the reputation of being catalytically inert to hydrocarbon transformations under the usual cracking conditions (5) and the participation of gold reactor walls in the reactions was thus considered to be insignificant or even absent. However, it should be mentioned that comparative experiments in a completely wall-less reactor of the type described earlier (2), both in the absence and in the presence of gold, have never been carried out, so that any statement about the complete inertness of gold under cracking conditions remains questionable.

During investigations carried out at the Eindhoven University of Technology on the thermal hydrocracking of individual polyaromatic compounds it was found that an AISI 316 stainless steel reactor wall could not be disregarded as a reaction partner (3). This was concluded from the effects observed with the ageing of the reactor wall, the temperature history and variations in the surface-to-volume ratio. In trying to evaluate the impact of AISI 316 stainless steel as a reactor wall material on the thermal hydrocracking of indan (a model substance used to investigate mechanism details of naphthenic ring hydrocracking) these experiments were repeated with a gold-lined reactor. This was made from plain carbon steel and electroplated inside with a gold layer having a thickness of approximately 2500 mono-atomic gold layers. Care was taken that all steel reactor parts coming into contact with hot hydrogen and/or indan were plated with gold. The gold plated reactor was of the flow type and had exactly the same dimensions as the AISI 316 reactor (a detailed description of the reaction system has previously been given (4)), so that, in comparing the performance of both reactors, differences in the hydrocracking pattern can be attributed merely to the difference in reactor wall material.

In the graphs the effects of AISI 316 and of gold as reactor wall materials are clearly illustrated. Both sets of experiments reveal the effects of reactor ageing. Data were obtained with reactors which had not previously been used. The procedure followed was to heat the reactor under a continuous flow of hydrogen of 80 bar until the reaction temperature of $500^{\circ} \mathrm{C}$ was established. At zero time the indan supply was started and held constant during the further experimental procedure.

It can be seen that initially the overall indan conversion is high but that it levels off to a steady value after an ageing time of approximately one hour. Also the yield of the different reaction products undergoes major changes with ageing time. Unaged AISI 316 causes the formation of a complex mixture of alkylbenzenes; after an ageing time of one hour the composition is significantly reduced to steady concentrations of mainly indene, toluene, $n$-propylbenzene, ethylbenzene, o-ethyltoluene and xylenes. Further ageing for around 400 hours had no further effect on this composition. The product composition indicates the occurrence of dehydrogenation, $\alpha$ ring opening and $\beta$-ring opening as leading primary reactions (4).

Ageing of the gold reactor has a completely different effect on the hydrocracking of indan. The graph shows clearly that the overall conversion of indan increases with ageing time, starting from an almost zero conversion at zero time. Even after two hours no 


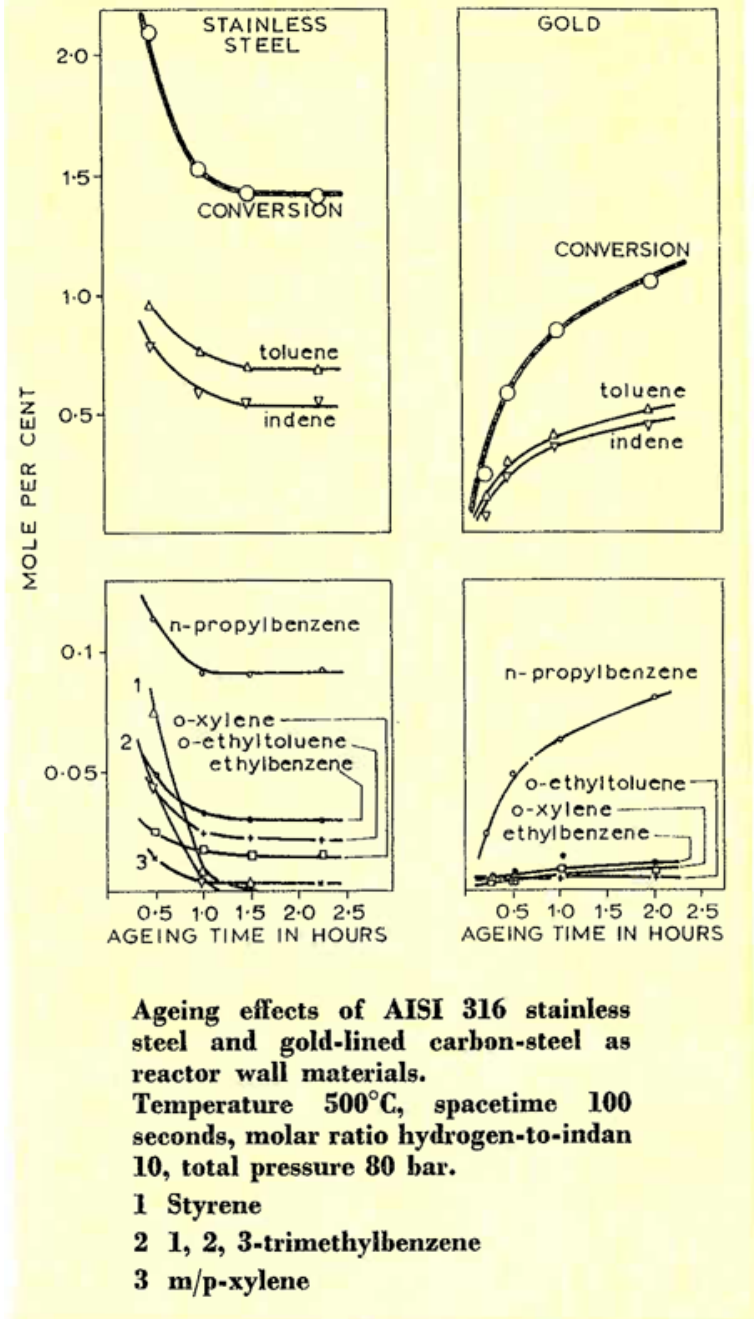

steady conversion level has been established, while the yield of the reaction products is quite different from that obtained with the stainless steel reactor; it varies only slightly with the ageing time, and the composition also indicates that with short ageing times only the three types of reactions previously mentioned are operative. It is interesting to see that the overall indan conversion and the product composition in the gold reactor tend to the steady state levels observed in the aged AISI 316 reactor. It may thus be concluded that the catalytic effects of both aged AISI 316 and gold are similar, although they differ quite significantly in the pre-aged stage.

This was tentatively explained by the formation of carbonaceous deposits on both the stainless steel and the gold during the ageing period (3). These deposits cover more active and less selective sites on the AISI 316 reactor wall, for example nickel and chromium crystallites, and provide new sites which are less active and more selective towards dehydrogenation, $\alpha$ - and $\beta$-ring opening. In the gold reactor no active sites are present initially, so that the conversion is very low. During ageing active sites of the type formed in the AISI 316 reactor are created, and cause the conversion to increase without a significant change in yield. Finally, both the AISI 316 and the gold are so transformed by ageing that the effect of either wall material is approximately equal on the hydrocracking of indan. The activity of steady-state reactor walls may be derived from free radicals which are likely to be present in carbonaceous coke deposits. Extrapolation of the conversion to zero time indicates a very low or even zero conversion.

This means that the thermal hydrocracking of indan, more particularly the $\alpha$-ring opening, proceeds with a significant rate only in the presence of a reactor wall with a specific activity; in other words although thermal hydrocracking proceeds homogeneously in the bulk of the fluid phase-because variation of the surface-to-volume ratio had no effect (3)it is most likely that the reactions are initiated heterogeneously at the wall of the reactor.

The author's present address is Akzo Chemie Nederland B.V., Amersfoort, The Netherlands.

\section{References}

1 B. L. Crijnes and L. F. Albright, Ind. Eng. Chem., Process Des. Dev., 1969, 8, 25

2 J. E. Taylor, D. M. Kulich, D. A. Hutchings, K. J. Frech and J. F. Kenneth, Abstracts, 163rd Nat. Mtg., Am. Chem. Soc., 1972, (April), PETR 033

$3 \mathrm{H}$. W. Slotboom and J. M. L. Penninger, Ind. Eng. Chem., Process Des. Dev., 1974, 13, (3) 296

4 J. M. L. Penninger and H. W. Slotboom, Rec. Trav. Chim. Pays Bas, 1973, 92, 513

5 Recently specific catalytic effects of gold layers in which hot electrons were produced were presented in J. Figar and W. Haidinger, Gold Bull., 1974, 7, (4) 100

\section{Selective Gold Catalysts}

While gold is not yet widely used in catalysis, its stability in acidic and alkaline media suggests that it has promise in certain specific processes as a highly selective catalyst. Gold's electronic configuration indicates that its catalytic activity will be less than that of various transition metals but gold on suitable supports may prove more efficient.

Studies have now been carried out by G. D. Kazakova, Yu. S. Mardashev and B. V. Erofeev at the Moscow State Pedagogic Institute named for V. I. Lenin and these show that $\mathrm{CaF}_{2}$ is superior as a support for gold compared with the other ionic supports $\mathrm{NaF}$, $\mathrm{KCl}, \mathrm{CsCl}, \mathrm{RbCl}, \mathrm{KI}$, and $\mathrm{BaCl}_{2}$ for the dehydrogenation of alcohols and for the conversions of benzene and cyclohexane (Dokl. Akad. Nauk S.S.S.R., 1975, 220, (5), 1106-1107).

Catalysts containing 0.3 per cent gold were tested for activity at 200 to $400^{\circ} \mathrm{C}$. Results showed that 0.3 per cent $\mathrm{Au} / \mathrm{CaF}_{2}$ had the highest activity for each dehydrogenation reaction and that this is connected with the greater stability of gold atoms in the crystal lattice of calcium flouride than in the other supports. 